\title{
Configuração Socioespacial na Região Metropolitana de Londrina (RML): uma análise da estrutura sócio-ocupacional - 2000 e 2010
}

\author{
Socio-Spatial Configuration in the Metropolitan Region of Londrina (RML): an \\ analysis of the socio-occupational structure - 2000 and 2010
}

Configuración Socioespacial en la Región Metropolitana de Londrina (RML): un análisis de la estructura socio-ocupacional - 2000 y 2010

\author{
Ana Lúcia Rodrigues ${ }^{1}$ \\ https://orcid.org/0000-0003-1582-374X \\ Olga Lúcia Castreghini de Freitas Firkowski ${ }^{2}$ \\ https://orcid.org/0000-0001-5840-2377 \\ Carla Franciele Höring ${ }^{3}$ \\ https://orcid.org/ 0000-0003-2572-8789
}

\begin{abstract}
RESUMO: Este artigo analisa o processo que resultou na atual configuração socioespacial da Região Metropolitana de Londrina-PR (RML), com os objetivos de descrever e analisar seu padrão de organização social e de ocupação socioespacial; as mudanças e permanências ocorridas na estrutura socioespacial da região entre 2000 e 2010 e o padrão histórico de organização dessa territorialidade. A metodologia utilizada é das Categorias Sócio-Ocupacionais - CATs, elaborada pelo Observatório das Metrópoles (IPPUR/UFRJ), por meio dos dados de Ocupação dos Microdados dos Censos Demográficos (IBGE, 2000 e 2010). Ficou evidenciado nas análises estatísticas e no georreferenciamento dos resultados, sistematizados nos quadros de evolução da composição da estrutura socioespacial da RML, que o padrão de organização socioespacial dessa região se caracteriza por periferização da população de baixa renda, e os trabalhadores das categorias que identificam as baixas posições da hierarquia social se distanciam da área central, proporcionalmente à sua posição na ocupação, no mundo do trabalho. Tal padrão também promoveu uma dinâmica que resultou, para ambos os períodos analisados, na ocupação das áreas centrais de Londrina, por tipos que representam as CATs das posições de hierarquia social superior.
\end{abstract}

PALAVRAS-CHAVE: Região Metropolitana de Londrina. Categorias Sócio-Ocupacionais. Estrutura Socioespacial. Ocupados.

\footnotetext{
${ }^{1}$ Doutora em Ciências Sociais - Sociologia pela PUC/SP. Professora do Programa de Pós-Graduação em Ciências Sociais na UEM. E-mail: alrodrigues1962@gmail.com.

${ }^{2}$ Doutora em Geografia pela USP. Professora do Programa de Pós-Graduação em Geografia na UFPR. E-mail: olgafirk@gmail.com.

${ }^{3}$ Mestre pelo Programa de Pós-Graduação em Agronomia pela Universidade Estadual do Oeste do Paraná UNIOESTE. Estatística do Observatório das Metrópoles-Núcleo UEM/Maringá. E-mail: estaticarla@gmail.com.
} 
ABSTRACT: This article analyzes the process that resulted in the current socio-spatial configuration of the Metropolitan Region of Londrina-PR (MRL), with the objective of describing and analyzing your pattern of social organization and socio-spatial occupation; It also analyzes the changes and permanencies that occurred on the socio-spatial structure of the region from 2000 to 2010, and the historical organization pattern of its territoriality. The used methodology is the Socio-Occupational Categories - SOCs, developed by the Observatory of the Metropolises (IPPUR/UFRJ), using Occupation data of the Microdata from the Demographic Census (IBGE, 2000 and 2010). It was evidenced in the statistical analyzes and in the georeferenced results systematized in the evolution tables of the composition of the socio-spatial structure of the MRL, that the pattern of socio-spatial organization in this region is characterized by the periphery of the low-income population, where workers in the categories that identify the low positions in the social hierarchy, distance themselves from the central area, proportionally to their position in the occupation, in the world of work. This pattern also promoted a dynamic that resulted, for both periods analyzed, in the occupation of the central areas of Londrina, by types that represent the CATs of the positions of higher social hierarchy.

KEYWORDS: Metropolitan Region of Londrina. Socio-Occupational Categories. Socio-spatial structure. Occupied.

RESUMEN: Este artículo analiza el proceso que resultó en la configuración socioespacial actual de la Región Metropolitana de Londrina-PR (RML), con el objetivo de describir y analizar tu patrón de organización social y ocupación socioespacial, los cambios y permanencias que ocurrieron en la estructura socioespacial de la región entre 2000 y 2010 y el patrón histórico de organización de esta territorialidad. La metodología utilizada proviene de las Categorías Socio-Ocupacionales-CAT, desarrolladas por el Observatorio de las Metrópolis (IPPUR / UFRJ), con datos de la Ocupación de los Microdatos de los Censos Demográficos (IBGE, 2000 y 2010). Se evidencia en los análisis estadísticos y en la georreferenciación de los resultados, sistematizados en las tablas de evolución de la composición de la estructura socioespacial del RML, que el patrón de organización socioespacial en esta región se caracteriza por la periferia de la población de bajos ingresos, donde se encuentran trabajadores en las categorías que identifican el posiciones bajas en la jerarquía social, se distancian del área central, proporcionalmente a su posición en la ocupación, en el mundo del trabajo. Este patrón también promovió una dinámica que resultó, para ambos períodos analizados, en la ocupación de las áreas centrales de Londrina, por tipos que representan a los CAT de los puestos de mayor jerarquía social.

PALABRAS-CLAVE: Región Metropolitana de Londrina. Categorías Socio-Ocupacionales. Estructura socioespacial. Ocupado.

\section{INTRODUÇÃO}

Este artigo se compõe de um estudo sobre a configuração socioespacial da Região Metropolitana de Londrina-PR $(R M L)$ e se realiza no âmbito da agenda de pesquisa da rede Observatório das Metrópoles (doravante apresentado pelas iniciais OM), sediado no IPPUR/UFRJ, e, em particular, por iniciativa dos núcleos de Maringá e Curitiba. Trata-se de um tema que se insere nas reflexões interdisciplinares sobre 0 processo de desenvolvimento urbano brasileiro, nas complexas conexões entre as tendências de segregação residencial e os mecanismos de reprodução das desigualdades sociais, por 
meio de aplicação de metodologia específica desenvolvida pela Rede. O objetivo é analisar o padrão de organização social e a consequente ocupação socioespacial do território metropolitano institucional de Londrina, por meio da espacialização do fenômeno social dado pela ocupação dos trabalhadores, bem como comparar as mudanças e permanências ocorridas na estrutura socioespacial da RML no período entre 2000 a 2010 e, por inferência, interpretar o padrão histórico de organização desse recorte territorial. Assim, o mercado de trabalho na RML será examinado com base numa estrutura hierarquizada de 24 Categorias Sócio-Ocupacionais (CATs), construídas a partir dos microdados dos Censos Demográficos de 2000 e 2010.

O estudo foi motivado pela perspectiva de aplicar à realidade de Londrina a mesma metodologia utilizada para análise das regiões metropolitanas de Curitiba e de Maringá, tendo em vista que Londrina é a única dentre as três principais regiões metropolitanas do estado a não integrar a rede $\mathrm{OM}$ e, por conseguinte, não ter sido objeto de desenvolvimento da pesquisa sobre sua estrutura socioespacial. A pesquisa desenvolvida nesse viés teórico adota pressupostos que admitem que o território reproduz e expressa a desigualdade social que caracteriza o capitalismo, especialmente por meio de um processo deliberado de preservação de espaços para ricos e de espaços para pobres, num círculo vicioso de reprodução do próprio sistema que, ao atuar assim, também alimenta a valorização imobiliária.

A partir dos dados censitários do IBGE foi construída uma tipologia socioespacial para a RML que explicita - ou não -, para esse recorte territorial institucional, a tendência à concentração periférica da moradia dos trabalhadores manuais e de baixos salários, como é característico do desenvolvimento urbano brasileiro. A organização social nas principais áreas urbanas do país resulta de três processos distintos: $1^{\circ}$ ) diferenciação, como parte constitutiva da estrutura capitalista; $2^{\circ}$ ) segmentação, por meio do acesso a determinado local de moradia conforme a condição econômica e, $3^{\circ}$ ) segregação, o processo deliberado dos gestores municipais que mantém espaços precários, em geral nas periferias urbanas, destituídos de equipamentos e de qualidade mínima, como contraponto aos territórios dotados de todas os equipamentos urbanos para distingui-los dos carentes e garantir alta valorização imobiliária. Ou seja, por meio da segregação socioespacial o solo urbano se torna mercadoria ao invés de ser o lócus da moradia e da produção.

Para a presente análise, os conteúdos do texto foram divididos em quatro partes, iniciando com uma breve Caracterização da Região Metropolitana de Londrina, seguida da explicitação da definição das Categorias Sócio-Ocupacionais, para a análise social do território e da descrição da construção da Tipologia Socioespacial: metodologia de definição, apresentando como foi construída a tipologia, bem como da definição da base geográfica, onde foram espacializadas as CATs, as Áreas de Ponderação (APONDs) do IBGE. O item 
Resultados, por sua vez, está dividido em dois: Estrutura e Perfil Social da Região Metropolitana de Londrina, onde são identificados os grandes grupos ocupacionais que representam a estrutura social dos trabalhadores da RML e Tipologia Socioespacial da Região Metropolitana de Londrina, onde apresenta-se a respectiva tipologia, a partir da qual são evidenciadas as alterações da composição desta estrutura social na região metropolitana.

\section{CARACTERIZAÇÃO DA REGIÃO METROPOLITANA DE LONDRINA - RML}

A RML está localizada no Norte do Estado do Paraná, que compõe a região Sul do Brasil (Figura 1 e Quadro 1). O crescimento demográfico regional é de $1 \%$ ao ano e a população estimada de 1.121 .303 , que corresponde a $9,74 \%$ do total da população do estado (IBGE, 2020). A região apresenta PIB per capita no valor de $R \$ 35.122$, menor que o do estado ( $R \$ 37.221)$ e o PIB a preços correntes correspondente a $9,1 \%$ do estadual (IPARDES, 2020). O valor adicionado fiscal da região se compõe por $17,2 \%$ oriundos de atividades relacionadas à produção do setor primário; 33,5\% da atividade industrial; 49,3\% relativos às atividades de comércio e serviços (IPARDES, 2020).

Observa-se, desde sua criação, a ampliação no número de municípios componentes da região metropolitana. Quando de sua institucionalização, em 1998, eram seis municípios integrantes, após os anos de 2010 uma série de inclusões foram realizadas, até que a RML alcançou os atuais 25 municípios, definidos pela Lei Complementar Estadual n. 167 de 02 de janeiro de 2014, a saber: Alvorada do Sul, Arapongas, Assaí, Bela Vista do Paraíso, Cambé, Centenário do Sul, Florestópolis, Guaraci, Ibiporã, Jaguapitã, Jataizinho, Londrina, Lupionópolis, Miraselva, Pitangueiras, Porecatu, Prado Ferreira, Primeiro de Maio, Rancho Alegre, Rolândia, Sabáudia, Sertaneja, Sertanópolis, Tamarana e Uraí (CASA CIVIL DO ESTADO DO PARANÁ, 2020).

A opção por trabalhar com esse recorte institucional, embora questionável na perspectiva acadêmica, como apontado por diversos autores (FIRKOWSKI \& MOURA, 2001; MOURA \& HOSHINO, 2015), exatamente pelo fato de que o mesmo é constituído muito mais por interesses políticos do que pela expressão espacial do processo socioespacial, se deve ao fato de que tem sido esse o recorte prioritário de desenvolvimento das análises da estrutura sócio-ocupacional realizadas pelo Observatório das Metrópoles. Assim, se trata de um alinhamento metodológico necessário e que tem norteado os trabalhos do OM para várias RM brasileiras, numa série temporal de cerca de 40 anos, desde a década de 1980. 
Figura 1 - Localização da Região Metropolitana de Londrina no Estado do Paraná-Brasil 2014
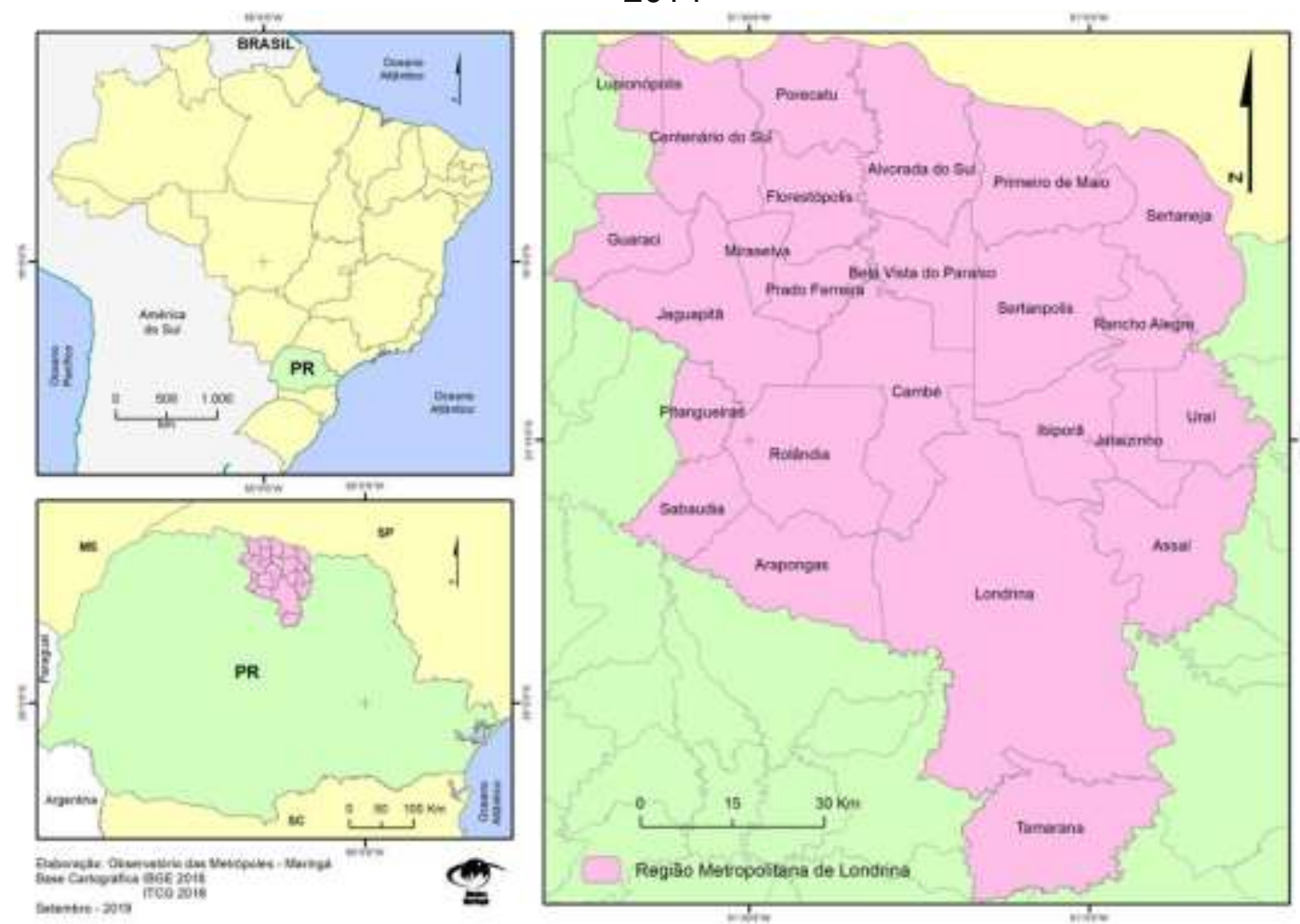

Fonte: Base Cartográfica - IBGE - 2018. Elaboração: Observatório das Metrópoles - Núcleo UEM/Maringá, 2020.

Quadro 1 - Composição da Região Metropolitana de Londrina segundo alterações da Legislação Estadual - 1998 a 2014

\begin{tabular}{|c|c|}
\hline $\begin{array}{l}\text { Lei Complementar Estadual n. } 81 \\
\text { de } 17 \text { de junho de } 1998\end{array}$ & Londrina, Cambé, Jataizinho, Ibiporã, Rolândia e Tamarana. \\
\hline $\begin{array}{l}\text { Lei Complementar Estadual n. } 86 \\
\text { de } 07 \text { de julho de } 2000\end{array}$ & Londrina, Cambé, Jataizinho, Ibiporã, Rolândia, Tamarana e Bela Vista do Paraíso. \\
\hline $\begin{array}{l}\text { Lei Complementar Estadual n. } 91 \\
\text { de } 05 \text { de junho de } 2002\end{array}$ & $\begin{array}{l}\text { Londrina, Cambé, Jataizinho, Ibiporã, Rolândia, Tamarana, Bela Vista do Paraíso e } \\
\text { Sertanópolis. }\end{array}$ \\
\hline $\begin{array}{l}\text { Lei Complementar Estadual n. } 129 \\
\text { de } 14 \text { de julho de } 2010\end{array}$ & $\begin{array}{l}\text { Londrina, Cambé, Jataizinho, Ibiporã, Rolândia, Tamarana, Bela Vista do Paraíso, } \\
\text { Sertanópolis, Primeiro de Maio, Alvorada do Sul e Assaí. }\end{array}$ \\
\hline $\begin{array}{l}\text { Lei Complementar Estadual n. } 144 \\
\text { de } 05 \text { de abril de } 2012\end{array}$ & $\begin{array}{l}\text { Londrina, Cambé, Jataizinho, Ibiporã, Rolândia, Tamarana, Bela Vista do Paraíso, } \\
\text { Sertanópolis, Primeiro de Maio, Alvorada do Sul, Assaí, Sabáudia, Jaguapitã e } \\
\text { Pitangueiras. }\end{array}$ \\
\hline $\begin{array}{l}\text { Lei Complementar Estadual n. } 147 \\
\text { de } 16 \text { de julho de } 2012\end{array}$ & $\begin{array}{l}\text { Londrina, Cambé, Jataizinho, Ibiporã, Rolândia, Tamarana, Bela Vista do Paraíso, } \\
\text { Sertanópolis, Primeiro de Maio, Alvorada do Sul, Assaí, Sabáudia, Jaguapitã, } \\
\text { Pitangueiras, Florestópolis e Porecatu. }\end{array}$ \\
\hline $\begin{array}{l}\text { Lei Complementar Estadual n. } 157 \\
\text { de } 09 \text { de julho de } 2013\end{array}$ & $\begin{array}{l}\text { Londrina, Cambé, Jataizinho, Ibiporã, Rolândia, Tamarana, Bela Vista do Paraíso, } \\
\text { Sertanópolis, Primeiro de Maio, Alvorada do Sul, Assaí, Sabáudia, Jaguapitã, } \\
\text { Pitangueiras, Florestópolis, Porecatu e Arapongas. }\end{array}$ \\
\hline $\begin{array}{l}\text { Lei Complementar Estadual n. } 165 \\
\text { de } 14 \text { de novembro de } 2013\end{array}$ & $\begin{array}{l}\text { Londrina, Cambé, Jataizinho, Ibiporã, Rolândia, Tamarana, Bela Vista do Paraíso, } \\
\text { Sertanópolis, Primeiro de Maio, Alvorada do Sul, Assaí, Sabáudia, Jaguapitã, } \\
\text { Pitangueiras, Florestópolis, Porecatu, Centenário do Sul, Guaraci, Lupionópolis, } \\
\text { Miraselva, Prado Ferreira, Uraí, Rancho Alegre e Sertaneja. }\end{array}$ \\
\hline $\begin{array}{l}\text { Lei Complementar Estadual n. } 167 \\
\text { de } 02 \text { de janeiro de } 2014\end{array}$ & $\begin{array}{l}\text { Londrina, Cambé, Jataizinho, Ibiporã, Rolândia, Tamarana, Bela Vista do Paraíso, } \\
\text { Sertanópolis, Primeiro de Maio, Alvorada do Sul, Assaí, Sabáudia, Jaguapitã, } \\
\text { Pitangueiras, Florestópolis, Porecatu, Centenário do Sul, Guaraci, Lupionópolis, } \\
\text { Miraselva, Prado Ferreira, Uraí, Rancho Alegre, Sertaneja e Arapongas. }\end{array}$ \\
\hline
\end{tabular}

Fonte: CASA CIVIL DO ESTADO DO PARANÁ, 2020. Elaboração: autoras, 2020. 


\section{CATEGORIAS SÓCIO-OCUPACIONAIS}

A perspectiva metodológica adotada pelo OM é sustentada no conceito de "espaço social" de Pierre Bourdieu (1997) e na sua afirmação de que a posição que o sujeito ocupa na estrutura produtiva é que irá determinar o patamar de acesso que terá aos bens materiais (renda e salário) e aos bens simbólicos (status e prestígio). Simultaneamente, "[...] como um espaço de posições sociais e um espaço de indivíduos ocupando esses postos e dotados de atributos sociais desigualmente distribuídos e ligados às suas histórias" (RIBEIRO e LAGO, 2000, p.12). Esses princípios teóricos orientadores engendraram a construção de uma estratificação social ancorada nos seguintes critérios: i) Relação capital $x$ trabalho; ii) Trabalho manual $x$ trabalho não-manual; iii) Trabalho de comando $x$ trabalho subordinado; iv) Trabalho público $x$ trabalho privado.

Com base nesses critérios, a metodologia de análise social do território utiliza a categoria ocupação - ocupação principal do indivíduo (IBGE, Microdados da Amostra do Censo Demográfico), cruzando-a com outras variáveis (renda, escolaridade, situação na ocupação, setor de atividade econômica e setor institucional) para definir uma estratificação social que resulta em vinte e quatro Categorias Sócio-ocupacionais (CATs), agrupadas em oito grandes grupos: 1) Dirigentes; 2) Profissionais de nível superior; 3) Pequenos empregadores; 4) Ocupações médias; 5) Trabalhadores do terciário especializado; 6) Trabalhadores do secundário; 7) Trabalhadores do terciário não especializado e 8) Trabalhadores agrícolas (RIBEIRO e RIBEIRO, 2013) (Quadro 2).

No grupo dos dirigentes estão os grandes empresários e profissionais de alto escalão; os profissionais de nível superior abrangem, como sugerido na denominação, os profissionais que ocupam cargos de exigem nível superior; o grupo dos pequenos empregadores reúne os empregadores por conta própria e aqueles que empregam menos de dez pessoas; no grupo das ocupações médias estão os técnicos e artistas, cujas ocupações requererem um conhecimento específico (como desenhistas, técnicos em energia elétrica, programadores de computação, músicos, fotógrafos etc.), as ocupações com algum poder de decisão (como assistentes de administração e corretores de imóvel), sem função decisória (como secretárias, auxiliares administrativos, etc.), nas áreas de saúde e educação (como professores de $1^{\circ}$ grau e enfermeiras não diplomadas) e trabalhadores nas áreas de segurança pública, justiça e correios (investigadores de polícia, oficiais do corpo de bombeiros, praças das forças armadas e carteiros); no grupo dos trabalhadores do terciário especializado estão as ocupações diretamente ligadas às atividades do comércio (como vendedores e operadores de caixa e pracistas) e prestadores de serviço especializado (ocupações manuais que requerem um saber específico como 
mecânicos, cabeleireiros e os empregados nos setores de prestação de serviços e administração pública, entre outros); no grupo dos trabalhadores do secundário estão os trabalhadores da indústria moderna, com exigência de maior qualificação (como os trabalhadores nas indústrias metalúrgica, mecânica, química e farmacêutica, entre outras), da indústria tradicional (dos demais ramos), dos serviços auxiliares (como os que atuam nos setores de transportes, comunicação, serviços auxiliares etc.) e os da construção civil (como mestres, pedreiros, pintores e serventes de pedreiro); no grupo do terciário nãoespecializado estão os prestadores de serviço (como porteiro, vigia etc.), trabalhadores domésticos, ambulantes e biscateiros (como feirantes, doceiros, guardadores de automóvel, engraxates e trabalhadores braçais autônomos, entre outros); por fim, o último grupo é composto pelos agricultores (RIBEIRO e LAGO, 2000).

Quadro 2 - Classificação da estratificação social do Observatório das Metrópoles, segundo as Categorias Sócio-Ocupacionais (CATs)

\begin{tabular}{|c|c|c|}
\hline GRUPOS & Código & Categorias sócio-ocupacionais \\
\hline \multirow{3}{*}{ Dirigentes } & CAT 21 & Grandes Empregadores \\
\hline & CAT 22 & Dirigentes do Setor Público \\
\hline & CAT 23 & Dirigentes do Setor Privado \\
\hline \multirow{4}{*}{$\begin{array}{l}\text { Profissionais } \\
\text { Superior }\end{array}$} & CAT 41 & Profissionais Autônomos de Nível Superior \\
\hline & CAT 42 & Profissionais Estatutários de Nível Superior \\
\hline & CAT 43 & Profissionais Empregados de Nível Superior \\
\hline & CAT 44 & Professores de Nível Superior \\
\hline Pequenos Empregadores & CAT 31 & Pequenos Empregadores \\
\hline \multirow{6}{*}{ Ocupações Médias } & CAT 32 & Artistas e similares \\
\hline & CAT 51 & Ocupações de Supervisão \\
\hline & CAT 52 & Ocupações de Escritório \\
\hline & CAT 53 & Ocupações Técnicas \\
\hline & CAT 54 & Ocupações da Saúde e Educação \\
\hline & CAT 55 & Ocupações da Justiça, Segurança Pública e Correios \\
\hline \multirow{2}{*}{$\begin{array}{l}\text { Trabalhadores } \\
\text { Especializado }\end{array}$} & CAT 61 & Trabalhadores do Comércio \\
\hline & CAT 62 & Prestadores de Serviços Especializados \\
\hline \multirow{4}{*}{$\begin{array}{l}\text { Trabalhadores } \\
\text { Secundário }\end{array}$} & CAT 71 & Trabalhadores da Indústria Moderna \\
\hline & CAT 72 & Trabalhadores da Indústria Tradicional \\
\hline & CAT 73 & Trabalhadores dos Serviços Auxiliares \\
\hline & CAT 74 & Operários da Construção Civil \\
\hline \multirow{3}{*}{$\begin{array}{l}\text { Trabalhadores do } \\
\text { Não-Especializado }\end{array}$} & CAT 63 & Prestadores de Serviços Não Especializados \\
\hline & CAT 81 & Ambulantes e Biscateiros \\
\hline & CAT 82 & Trabalhadores Domésticos \\
\hline Trabalhadores Agrícolas & CAT 10 & Agricultores \\
\hline
\end{tabular}

Fonte: RIBEIRO e RIBEIRO (2013, p.31).

\section{TIPOLOGIA SOCIOESPACIAL: METODOLOGIA DE DEFINIÇÃO}

A Tipologia Socioespacial é construída considerando, sobretudo, a ocupação dos trabalhadores, sua renda e seu nível de instrução e o local de residência classificado de acordo com as características da população ocupada (RIBEIRO e RIBEIRO, 2013). Para a definição da base geográfica, onde foram espacializadas as Categorias Sócio-Ocupacionais 
(CATs) - que expressam as características socioespaciais do lugar de moradia dos ocupados - são utilizadas as APONDs, que são unidades geográficas compostas por agrupamentos de setores censitários, construídas pelo IBGE, a partir dos seguintes critérios: i) a princípio, cada município é uma área de ponderação; ii) municípios maiores foram subdivididos automaticamente respeitando os critérios de vizinhança entre setores censitários e tamanho mínimo da área de ponderação e; iii) para alguns municípios foram definidas frações amostrais distintas visando garantir a qualidade das estimativas para algumas áreas de interesse e, portanto, cada uma dessas áreas foi definida como uma área de ponderação (IBGE, 2010).

A análise do padrão de organização social do território da Região Metropolitana de Londrina foi realizada por meio da espacialização das tipologias sócio-ocupacionais construídas e territorializadas de forma desagregada por Áreas de Ponderação - APONDs (IBGE, 2000 e 2010). No ano de 2000, o município de Londrina era dividido em 23 APONDs; Arapongas e Cambé, ambos, divididos em cinco APONDs, enquanto os demais 22 municípios correspondiam cada qual a uma única área, perfazendo um total de 55 áreas de ponderação. Em 2010, o total de APONDs da RML diminuiu de 55 para 42, tendo em vista as análises ponderadas realizadas pelo IBGE, que resultou em nova agregação de setores censitários homogêneos, conforme se apresenta adiante. Ou seja, essa territorialização traz, em si mesma, uma leitura social do espaço, à medida que se constitui em agrupamento estatístico de setores censitários com algumas informações demográficas e socioeconômicas homogêneas, sendo o setor censitário, por sua vez, correspondente à menor unidade territorial desagregada utilizada para o Censo (Figura 2).

Para elaboração da tipologia socioespacial foram utilizados dois procedimentos: i) análise de correspondência binária e; ii) análise de clusters, técnicas correspondentes à análise multivariada. A análise de correspondência diz respeito a um tipo de análise fatorial aplicada a dados discretos (RIBEIRO e RIBEIRO, 2013).

A identificação das associações entre as CATs e as APONDs se utiliza da análise de correspondência e da técnica da análise multivariada, que permitem estabelecer relações, as quais, em geral, não seriam detectadas em comparações aos pares destas mesmas variáveis, por outras técnicas da estatística descritiva (RODRIGUES; ACORSI e SOUZA, 2015).

A análise de cluster é complementar à análise de correspondência na aplicação da tipologia socioespacial, por contribuir para definição dos agrupamentos territoriais formados. Para nomear esses grupos, utiliza-se estatística descritiva considerando a distribuição percentual de cada uma das áreas de ponderação segundo as CATs e densidade relativa de 
cada APOND, ou seja, o peso que cada CAT, de cada área, possui em relação ao total de indivíduos (RIBEIRO e RIBEIRO, 2013).

Figura 2 - Base territorial da Região Metropolitana de Londrina por APONDs
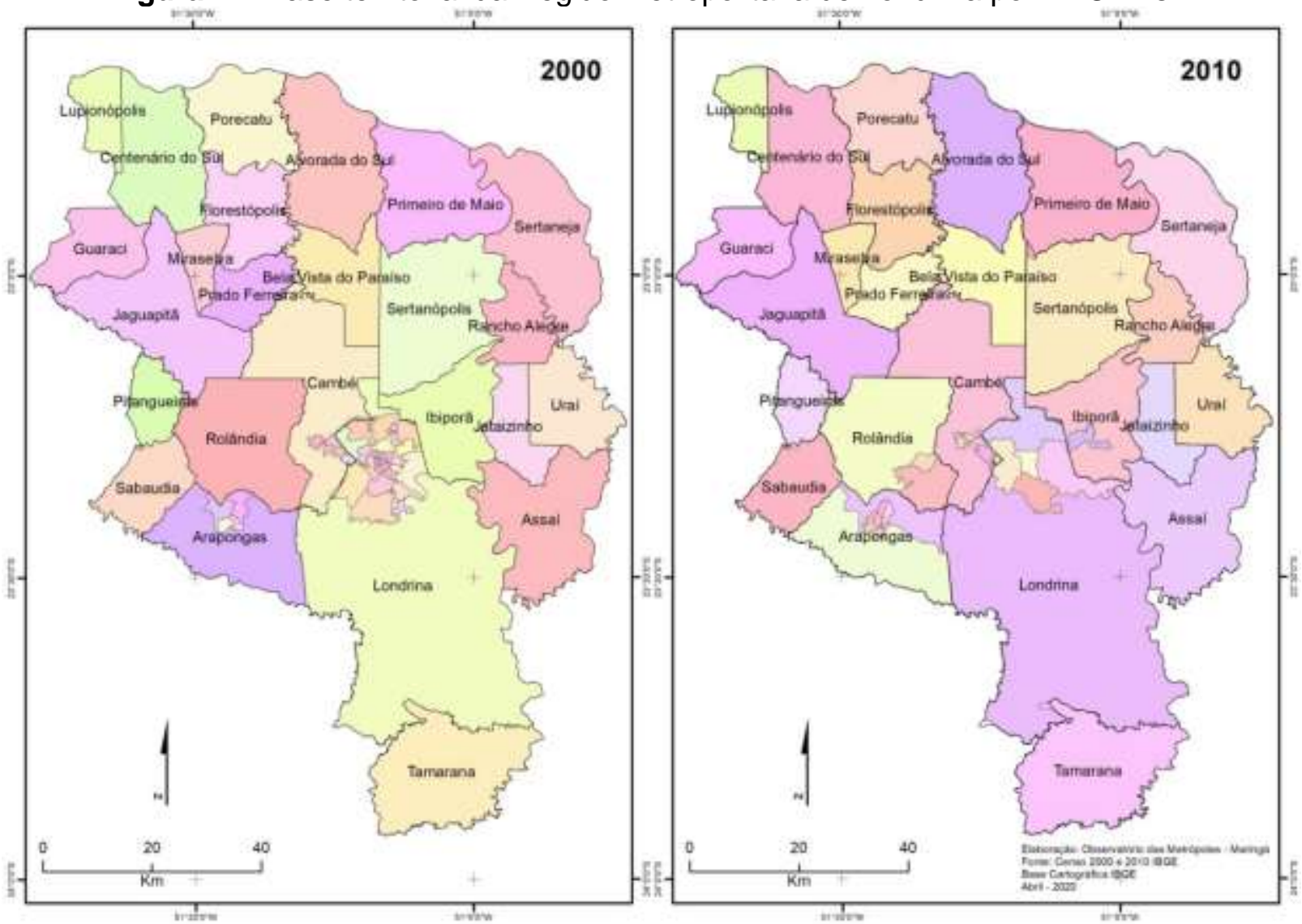

Fonte: Base Cartográfica - IBGE - 2018. Elaboração: Observatório das Metrópoles - Núcleo UEM/Maringá, 2020.

\section{RESULTADOS}

\section{Estrutura e perfil social da Região Metropolitana de Londrina}

O perfil social do território da Região Metropolitana de Londrina na década 2000 a 2010 foi analisado a partir das CATs, construídas como proxy da estrutura social deste território institucional, aplicadas para identificar esta estrutura e mostrá-la em dimensão espacial, por meio das ocupações dos trabalhadores e suas variações ao longo do período analisado. Nos resultados foi somado o número de trabalhadores identificados por sua CAT, nas APONDs.

Apresentam-se a seguir os grandes grupos ocupacionais que representam a estrutura social dos trabalhadores da Região Metropolitana de Londrina (RML) no período de 2000 e de 2010, bem como a sua variação neste período (diferença \% 2010-2000) (Tabela 1). 
Tabela 1 - Estrutura social da Região Metropolitana de Londrina por grandes grupos das CATs - 2000 e 2010

\begin{tabular}{l|c|c|c|c|c|c}
\hline \multirow{2}{*}{ CATEGORIAS SÓCIO-OCUPACIONAIS } & \multicolumn{3}{|c}{ ANO } & \multicolumn{2}{c}{ DIFERENÇA } \\
\cline { 2 - 7 } & \multicolumn{2}{|c|}{$\mathbf{2 0 0 0} \mathbf{2 0 1 0}$} & \multicolumn{2}{c}{$\mathbf{2 0 1 0 - 2 0 0 0}$} \\
\cline { 2 - 7 } & $\mathbf{N}$ & $\%$ & $\mathbf{N}$ & $\%$ & $\mathbf{2}$ & 9,1 \\
\hline 1 - Dirigentes & 6.981 & 1,8 & 7.617 & 1,6 & 635 & 110,7 \\
\hline 2 - Profissionais de Nível Superior & 21.132 & 5,4 & 44.525 & 9,2 & 23.393 & $-17,3$ \\
\hline 3 - Pequenos Empregadores & 11.759 & 3,0 & 9.724 & 2,0 & -2.036 & 42,3 \\
\hline 4 - Ocupações Médias & 82.513 & 21,0 & 117.450 & 24,3 & 34.937 & 9,8 \\
\hline 5 - Trabalhadores do Terciário & 61.836 & 15,8 & 67.890 & 14,0 & 6.054 & 34,5 \\
\hline 6specializado - Trabalhadores do Secundário & 96.985 & 24,7 & 130.487 & 27,0 & 33.502 & 7,2 \\
\hline 7 - Trabalhadores do Terciário Não- & 66.961 & 17,1 & 71.801 & 14,9 & 4.839 & $-23,6$ \\
\hline Especializado - Trabalhadores Agrícolas & 44.386 & 11,3 & 33.898 & 7,0 & -10.489 & $\mathbf{2 3 , 1}$ \\
\hline
\end{tabular}

Fonte: IBGE - Microdados dos Censos Demográficos - 2000 e 2010. Elaboração: autoras, 2020.

Nota-se que houve aumento de $23,1 \%$ de ocupados nessa região, passando de 392.554 trabalhadores em 2000 para 483.390 em 2010. O grupo de trabalhadores do secundário (indústria) representa o maior percentual dos empregados no ano 2000, com $24,7 \%$ dos ocupados; em seguida está o grupo das ocupações médias com $21,0 \%$ dos trabalhadores. No ano de 2010 os trabalhadores do secundário continuam predominantes, com $27,0 \%$ dos ocupados e, como na década anterior, em seguida aparecem as ocupações médias, com $24,3 \%$ dos ocupados no período. A categoria dirigentes foi a que menos empregou nos dois momentos, com 1,8\% em 2000 e 1,6\% em 2010.

Com relação às mudanças entre 2000 a 2010, observa-se que houve aumento de $110,7 \%$ dos profissionais de nível superior na RML; seguido de aumento de $42,3 \%$ das ocupações médias e, em sentido contrário, os trabalhadores agrícolas sofreram o maior decréscimo no período avaliado, com redução de $-23,6 \%$.

$\mathrm{Na}$ Tabela 2 estão apresentados os dados desagregados para os subgrupos que compõem cada um destes oito grandes grupos que constituem as 24 CATs (2000 e 2010) que mostram em detalhe a mudança ocorrida no período. Verifica-se que houve aumento de $11,5 \%$ no total da população da RML, passando de 897.086 moradores em 2000 para 1.000 .062 em 2010 e um crescimento de $23,1 \%$ dos ocupados, inclusive com um aumento percentual dos ocupados maior que o da população. Nas ocupações do secundário predominam os operários da construção civil, com 7,8\% em 2000 e 8,3\% em 2010 e dos serviços auxiliares, que aumentou de $5,8 \%$ para $8,4 \%$ no período. Dentre as ocupações médias, os de escritório foram a ocupação que mais incorporou mão de obra, com 7,8\% em 2000 e $9,1 \%$ em 2010. 
Tabela 2 - Estrutura social da Região Metropolitana de Londrina, por categorias sócioocupacionais - 2000 e 2010

\begin{tabular}{|c|c|c|c|c|c|c|}
\hline \multirow{3}{*}{$\begin{array}{c}\text { CATEGORIAS } \\
\text { SÓCIO-OCUPACIONAIS }\end{array}$} & \multicolumn{4}{|c|}{ ANO } & \multirow{2}{*}{\multicolumn{2}{|c|}{$\begin{array}{c}\text { DIFERENÇA } \\
2010-2000\end{array}$}} \\
\hline & \multicolumn{2}{|c|}{2000} & \multicolumn{2}{|c|}{2010} & & \\
\hline & $\mathbf{N}$ & $\%$ & $\mathbf{N}$ & $\%$ & $\mathbf{N}$ & $\%$ \\
\hline DIRIGENTES & 6.981 & 1,8 & 7.617 & 1,6 & 635 & 9,1 \\
\hline \begin{tabular}{l|l} 
CAT 21 & Grandes empregadores
\end{tabular} & 5.099 & 1,3 & 6.175 & 1,3 & 1.076 & 21,1 \\
\hline CAT 22 Dirigentes do setor público & 614 & 0,2 & 850 & 0,2 & 236 & 38,4 \\
\hline CAT 23 Dirigentes do setor privado & 1.268 & 0,3 & 591 & 0,1 & -677 & $-53,4$ \\
\hline PROFISSIONAIS DE NÍVEL SUPERIOR & 21.132 & 5,4 & 44.525 & 9,2 & 23.393 & 110,7 \\
\hline \begin{tabular}{l|l} 
CAT 41 & Profissionais autônomos de nível superior
\end{tabular} & 4.824 & 1,2 & 10.529 & 2,2 & 5.705 & 118,3 \\
\hline CAT 42 Profissionais empregados de nível superior & 6.821 & 1,7 & 17.145 & 3,5 & 10.324 & 151,3 \\
\hline CAT 43 Profissionais estatutários de nível superior & 1.411 & 0,4 & 2.202 & 0,5 & 791 & 56,1 \\
\hline CAT 44 Professores de nível superior & 8.076 & 2,1 & 14.649 & 3,0 & 6.573 & 81,4 \\
\hline PEQUENOS EMPREGADORES & 11.759 & 3,0 & 9.724 & 2,0 & -2.036 & $-17,3$ \\
\hline \begin{tabular}{l|l} 
CAT 31 & Pequenos empregadores \\
\end{tabular} & 11.759 & 3,0 & 9.724 & 2,0 & -2.036 & $-17,3$ \\
\hline OCUPAÇÕES MÉDIAS & 82.513 & 21,0 & 117.450 & 24,3 & 34.937 & 42,3 \\
\hline \begin{tabular}{l|l} 
CAT 51 & Ocupações de escritório
\end{tabular} & 30.434 & 7,8 & 43.752 & 9,1 & 13.318 & 43,8 \\
\hline CAT 52 Ocupações de supervisão & 12.705 & 3,2 & 25.978 & 5,4 & 13.273 & 104,5 \\
\hline CAT 53 Ocupações técnicas & 18.966 & 4,8 & 24.425 & 5,1 & 5.458 & 28,8 \\
\hline CAT 54 Ocupações da saúde e educação & 12.124 & 3,1 & 15.061 & 3,1 & 2.937 & 24,2 \\
\hline CAT 55 Ocupações de segurança, justiça e correios & 4.083 & 1,0 & 2.799 & 0,6 & -1.284 & $-31,4$ \\
\hline CAT 32 Ocupações artísticas e similares & 4.201 & 1,1 & 5.436 & 1,1 & 1.235 & 29,4 \\
\hline TRABALHADORES DO TERCIÁRIO ESPECIALIZADO & 61.836 & 15,8 & 67.890 & 14,0 & 6.054 & 9,8 \\
\hline \begin{tabular}{l|l} 
CAT 61 & Trabalhadores do comércio \\
\end{tabular} & 31.242 & 8,0 & 41.059 & 8,5 & 9.817 & 31,4 \\
\hline CAT 62 Prestadores de serviços especializados & 30.594 & 7,8 & 26.831 & 5,6 & -3.763 & $-12,3$ \\
\hline TRABALHADORES DO SECUNDÁRIO & 96.985 & 24,7 & 130.487 & 27,0 & 33.502 & 34,5 \\
\hline \begin{tabular}{l|l} 
CAT 71 & Trabalhadores da indústria moderna
\end{tabular} & 19.161 & 4,9 & 24.106 & 5,0 & 4.945 & 25,8 \\
\hline CAT 72 Trabalhadores da indústria tradicional & 24.631 & 6,3 & 25.738 & 5,3 & 1.106 & 4,5 \\
\hline CAT 73 Trabalhadores dos serviços auxiliares & 22.595 & 5,8 & 40.497 & 8,4 & 17.901 & 79,2 \\
\hline CAT 74 Operários da construção civil & 30.597 & 7,8 & 40.147 & 8,3 & 9.549 & 31,2 \\
\hline TRABALHADORES DO TERCIÁRIO NÃO-ESPECIALIZAI & 66.961 & 17,1 & 71.801 & 14,9 & 4.839 & 7,2 \\
\hline \begin{tabular}{l|l} 
CAT 63 & Prestadores de serviços não-especializados
\end{tabular} & 18.734 & 4,8 & 33.501 & 6,9 & 14.768 & 78,8 \\
\hline CAT 81 Empregados domésticos & 33.234 & 8,5 & 31.511 & 6,5 & -1.723 & $-5,2$ \\
\hline CAT 82 Ambulantes e biscateiros & 14.994 & 3,8 & 6.789 & 1,4 & -8.205 & $-54,7$ \\
\hline TRABALHADORES AGRÍCOLAS & 44.386 & 11,3 & 33.898 & 7,0 & -10.489 & $-23,6$ \\
\hline \begin{tabular}{l|l} 
CAT 10 & Agricultores \\
\end{tabular} & 44.386 & 11,3 & 33.898 & 7,0 & -10.489 & $-23,6$ \\
\hline TOTAL DE OCUPADOS & 392.554 & 100,0 & 483.390 & 100,0 & 90.836 & 23,1 \\
\hline POPULAÇÃO & 897.086 & - & 1.000 .062 & - & 102.976 & 11,5 \\
\hline
\end{tabular}

Fonte: IBGE - Microdados dos Censos Demográficos - 2000 e 2010. Elaboração: autoras, 2020.

Em oposição, a categoria de ocupados que menos empregou no ano de 2000 foi dos dirigentes tanto do setor público $(0,2 \%)$ como do setor privado $(0,3 \%)$, além dos profissionais estatutários de nível superior (0,4\%). Da mesma forma, no ano de 2010 , os dirigentes do setor privado representaram $0,1 \%$ e do setor público permaneceu em $0,2 \%$ do total dos ocupados da RML.

Os profissionais empregados de nível superior foram os que mais ampliaram participação no mercado de trabalho da RML, pois, no período entre 2000 e 2010, apresentaram um incremento de $151,3 \%$, passando de $6.821(1,7 \%)$ ocupados para 17.145 $(3,5 \%)$, respectivamente, neste período. Por outro lado, os dirigentes do setor privado sofreram decréscimo de $-53,4 \%$, passando de 1.268 trabalhadores em 2000 para 591 em 2010.

Como podemos observar pelos dados, a distribuição das CATs na Região Metropolitana de Londrina, em 2000, estava concentrada nos grupos trabalhadores do 
secundário, seguido das ocupações médias. As categorias dos dirigentes e dos pequenos empregadores apresentavam baixa concentração. Em 2010, a distribuição das categorias sócio-ocupacionais da RML permaneceu concentrada nos trabalhadores do secundário (27\%) seguida das ocupações médias (24,3\%). Os trabalhadores agrícolas e os pequenos empregadores sofreram queda nas ocupações, com percentuais negativos de $-23,6 \%$ e $17,3 \%$, respectivamente. Importante notar o crescimento significativo dos profissionais de nível superior, passando de $21.132(5,4 \%)$ trabalhadores em 2000 para $44.525(9,2 \%)$ em 2010.

Depreende-se dessa descrição que a composição sócio-ocupacional da Região Metropolitana de Londrina experimentou permanências e mudanças no período entre 2000 a 2010 expressas na sua estrutura social. Destacam-se as seguintes: i) em 2010 continua baixa a participação da categoria dos dirigentes; ii) ocorre o crescimento expressivo dos profissionais de nível superior entre 2000 e 2010 e principalmente dos profissionais empregados de nível superior; iii) o percentual de pequenos empregadores apresentou queda de $-17,3 \%$ no período; iv) aumento das ocupações médias são puxadas pelas ocupações de supervisão e de escritório; v) crescimento da categoria dos trabalhadores do terciário especializado, representado pelo aumento dos trabalhadores no comércio; vi) aumento importante de trabalhadores do secundário, tanto dos serviços auxiliares como dos operários da construção civil; porém com menor participação de trabalhadores atuando na indústria tradicional no ano de 2010; vii) crescimento do índice de prestadores de serviços não especializados em 78,8\%; viii) declínio percentual do número de ambulantes e biscateiros e de empregados domésticos; ix) queda no número de trabalhadores agrícolas, apesar de esta categoria ainda incorporar $7 \%$ dos ocupados na região metropolitana, em 2010.

\section{Tipologia socioespacial da Região Metropolitana de Londrina}

A análise social do território relativa às mudanças do perfil social da região no período 2000 a 2010, realizada na seção anterior, resultou na elaboração da tipologia socioespacial para a RML, com a qual se evidenciam as alterações da composição desta estrutura social regional. Os resultados das densidades relativas das 24 CATs foram utilizados para dar os nomes aos tipos sócio-ocupacionais, a partir de maior ou menor presença das determinadas categorias ocupacionais em cada um deles.

Assim, obteve-se a Tipologia Socioespacial a partir da distribuição percentual e localização residencial dos trabalhadores da região com o número absoluto de ocupados 
alocados nas 24 CATs, por APOND, para 2000 e para 2010. A análise de correspondência foi elaborada para identificar a quantidade de fatores que seriam formados a partir da correlação entre essas variáveis, bem como as suas contribuições em 2000 e 2010. Para complementar, a partir da análise de cluster, formaram-se três grupos na RML em 2000 e em 2010, cuja variabilidade entre eles foi de $17 \%$ e $20 \%$, respectivamente nos anos, ou seja, a metodologia garantiu semelhanças entre os agrupamentos. Os grupos foram classificados em três tipos socioespaciais: Superior Médio, Operário Popular e Agrícola e georreferenciados nas 55 APONDs que compunham o território da RM de Londrina em 2000 e nas 42 áreas em 2010.

O tipo Superior Médio foi caracterizado por ter concentração relativa das categorias pertencentes aos dirigentes, profissionais de nível superior e pequenos empregadores, mas, do mesmo modo, influência da densidade do grupo de ocupações médias. O tipo Operário Popular possui predominância dos grupos de trabalhadores do secundário e, também, dos trabalhadores do terciário especializado e não especializado e o tipo Agrícola, representado pelos trabalhadores agrícolas, com elevada densidade nessa categoria (Tabela 3).

Tabela 3 - Densidade relativa da tipologia socioespacial segundo as categorias Sócioocupacionais da Região Metropolitana de Londrina - 2000 e 2010

\begin{tabular}{|c|c|c|c|c|c|c|c|}
\hline \multirow{3}{*}{\multicolumn{2}{|c|}{$\begin{array}{c}\text { CATEGORIAS } \\
\text { SÓCIO-OCUPACIONAIS }\end{array}$}} & \multicolumn{6}{|c|}{ TIPOS SOCIOESPACIAIS } \\
\hline & & \multicolumn{2}{|c|}{ SUPERIOR MÉDIO } & \multicolumn{2}{|c|}{ OPERÁRIO POPULAR } & \multicolumn{2}{|c|}{ AGRÍCOLA } \\
\hline & & 2000 & 2010 & 2000 & 2010 & 2000 & 2010 \\
\hline CAT21 & Grandes Empregadores & 3,66 & 1,74 & 0,56 & 0,40 & 0,40 & 0,39 \\
\hline CAT22 & Dirigentes do Setor Público & 2,19 & 1,09 & 0,60 & 0,71 & 1,29 & 1,76 \\
\hline CAT23 & Dirigentes do Setor Privado & 4,67 & 1,94 & 0,30 & 0,18 & 0,42 & 0,47 \\
\hline CAT41 & Profissionais Autônomos de Nível Superior & 3,81 & 1,78 & 0,52 & 0,36 & 0,40 & 0,41 \\
\hline CAT42 & Profissionais Empregados de Nível Superior & 3,47 & 1,55 & 0,58 & 0,59 & 0,47 & 0,42 \\
\hline CAT43 & Profissionais Estatutários de Nível Superior & 3,92 & 1,76 & 0,48 & 0,39 & 0,43 & 0,34 \\
\hline CAT44 & Professores de Nível Superior & 2,79 & 1,40 & 0,63 & 0,62 & 0,80 & 0,88 \\
\hline CAT31 & Pequenos Empregadores & 2,55 & 1,35 & 0,69 & 0,68 & 0,79 & 0,84 \\
\hline CAT51 & Ocupações de Escritório & 1,59 & 1,21 & 1,03 & 0,91 & 0,52 & 0,50 \\
\hline CAT52 & Ocupações de Supervisão & 1,79 & 1,29 & 0,92 & 0,83 & 0,68 & 0,51 \\
\hline CAT53 & Ocupações Técnicas & 1,90 & 1,29 & 1,00 & 0,84 & 0,39 & 0,46 \\
\hline CAT54 & Ocupações da Saúde e Educação & 1,18 & 1,26 & 1,04 & 0,81 & 0,78 & 0,71 \\
\hline CAT55 & Ocupações de Segurança, Justiça e Correios & 1,54 & 1,33 & 1,02 & 0,78 & 0,57 & 0,52 \\
\hline CAT32 & Ocupações Artísticas e Similares & 1,77 & 1,22 & 0,96 & 0,90 & 0,57 & 0,51 \\
\hline CAT61 & Trabalhadores do Comércio & 0,96 & 1,03 & 1,09 & 1,04 & 0,78 & 0,72 \\
\hline CAT62 & Prestadores de Serviços Especializados & 0,66 & 1,06 & 1,21 & 1,00 & 0,65 & 0,76 \\
\hline CAT71 & Trabalhadores da Indústria Moderna & 0,45 & 0,71 & 1,25 & 1,27 & 0,70 & 1,08 \\
\hline CAT72 & Trabalhadores da Indústria Tradicional & 0,52 & 0,78 & 1,21 & 1,25 & 0,73 & 0,89 \\
\hline CAT73 & Trabalhadores dos Serviços Auxiliares & 0,40 & 0,70 & 1,22 & 1,33 & 0,79 & 0,92 \\
\hline CAT74 & Operários da Construção Civil & 0,34 & 0,79 & 1,24 & 1,25 & 0,79 & 0,89 \\
\hline САT63 & Prestadores de Serviços Não-Especializados & 0,44 & 0,89 & 1,22 & 1,17 & 0,78 & 0,75 \\
\hline САТ 81 & Empregados Domésticos & 0,41 & 0,86 & 1,15 & 1,10 & 0,98 & 1,16 \\
\hline САT 82 & Ambulantes e Biscateiros & 0,93 & 0,99 & 1,17 & 1,09 & 0,57 & 0,71 \\
\hline CAT10 & Agricultores & 0,11 & 0,26 & 0,38 & 0,90 & 3,34 & 4,31 \\
\hline
\end{tabular}

Fonte: IBGE - Microdados dos Censos Demográficos - 2000 e 2010. Elaboração: autoras, 2020.

Em detalhe se observa que o tipo que agrega moradores da hierarquia social superior se compõe em 2000 de dirigentes dos setores públicos e privados e profissionais de nível 
superior e, ao contrário, tem baixa presença de moradores da base da hierarquia social. Em 2010 essa característica socioespacial se mantém, todavia observa-se que a densidade dessas ocupações é menor que na década anterior. Isso significa que, neste último ano da análise, há menor concentração espacial das classes exclusivamente superiores que partilham os mesmos territórios com as classes médias.

As áreas classificadas como tipo Operário Popular apresentam as mesmas características nos dois períodos, com uma composição de moradores que atuam nas ocupações da indústria e nas do comércio e serviços. Observa-se pequena diminuição dos ocupados no terciário, tanto nos serviços especializados como naqueles não-especializados, assim como também nas ocupações dos ambulantes e dos empregados domésticos.

O tipo Agrícola caracteriza áreas em que a densidade destas ocupações é muito significativa, ou seja, são locais com importante presença destes ocupados, maior ainda em 2010, quando também se observa um crescimento de moradores em empregos domésticos. Nos dois períodos este tipo apresenta também moradores dirigentes do setor público, com maior presença em 2010.

A partir da identificação e construção da tipologia socioespacial da região de Londrina foi possível estabelecer a relação desta tipologia com a localização espacial da população e população ocupada, nos períodos 2000 e 2010 (Tabela 4).

Em 2000, o tipo Superior Médio inclui sete áreas de Londrina e uma de Arapongas que concentram 127.252 moradores. Destaca-se o tipo Operário Popular que agrega o maior contingente de moradores (560.907) e abrange a maior área, incluindo 26 APONDs, sendo: quinze de Londrina; quatro de Arapongas, quatro de Cambé e os municípios de Ibiporã, Jataizinho e de Rolândia. No tipo Agrícola residem 208.927 habitantes. Constitui-se por uma APOND de Londrina, uma de Cambé e todas as demais 19 áreas são constituídas pelos restantes 19 municípios da região, cada qual classificado como uma APOND.

Em 2010, a Tipologia Socioespacial se altera nas APONDs em relação a 2000. São nove áreas de hierarquia superior, classificadas de tipo Superior Médio, sendo quatro APONDs de Londrina; duas de Arapongas e uma respectivamente em Cambé, Ibiporã e Rolândia. As áreas desse tipo incorporam o maior contingente populacional da região, um total de 441.201 habitantes sendo desses, 217.268 ocupados.

O tipo Operário Popular inclui 19 áreas, essas compostas por quatro de Arapongas, quatro de Cambé, duas de Rolândia, uma APOND de Londrina e de lbiporã, bem como em outros sete municípios distintos da RML, dentre eles, Bela Vista do Paraíso, Florestópolis, Jaguapitã, Jataizinho Lupionópolis, Porecatu e Sertanópolis, também incorporando um total expressivo de população com 435.732 habitantes, sendo 211.354 os ocupados. O tipo Agrícola tem população de 123.129 pessoas distribuídas em 14 municípios da RML, são 
eles: uma APOND de Londrina, Alvorada do Sul, Assaí, Centenário do Sul, Guaraci, Miraselva, Pitangueiras, Prado Ferreira, Primeiro de Maio, Rancho Alegre, Sabáudia, Sertaneja, Tamarana e Uraí. As informações a seguir possibilitam uma comparação da composição dos tipos, considerando as mudanças no período entre 2000 e 2010 (Tabela 5).

Tabela 4 - Tipologia socioespacial segundo população e população ocupada por APONDs dos municípios da Região Metropolitana de Londrina - 2000 e 2010

\begin{tabular}{|c|c|c|c|c|c|c|}
\hline $\begin{array}{l}\text { TIPOLOGIA SOCIOESPACIAL } \\
(\mathbf{2 0 0 0 )}\end{array}$ & $\begin{array}{c}\text { ÁREA DE } \\
\text { PONDERAÇÃo }\end{array}$ & MUNICÍPIO & POPULAÇÃO & $\begin{array}{l}\text { PERCENTUAL DA } \\
\text { POPULAÇÃO }\end{array}$ & $\begin{array}{l}\text { POPULAÇÃO } \\
\text { OCUPADA }\end{array}$ & $\begin{array}{l}\text { PERCENTUAL DA } \\
\text { POPULAÇÃOO } \\
\text { OCUPADA }\end{array}$ \\
\hline \multirow{9}{*}{$\begin{array}{l}\text { SUPERIOR } \\
\text { MÉDIO }\end{array}$} & 4101507001003 & Arapongas3 & 16.248 & 12,8 & 7.598 & 12,6 \\
\hline & 4113700999009 & Londrina9 & 23.481 & 18,5 & 11.160 & 18,5 \\
\hline & 4113700999010 & Londrina10 & 12.963 & 10,2 & 6.172 & 10,2 \\
\hline & 4113700999011 & Londrina11 & 13.584 & 10,7 & 6.165 & 10,2 \\
\hline & 4113700999013 & Londrina13 & 16.121 & 12,7 & 7.404 & 12,3 \\
\hline & 4113700999018 & Londrina18 & 12.099 & 9,5 & 6.097 & 10,1 \\
\hline & 4113700999019 & Londrina19 & 13.759 & 10,8 & 6.726 & 11,1 \\
\hline & \multirow[t]{2}{*}{4113700999020} & Londrina20 & 18.997 & 14,9 & 9.087 & 15,0 \\
\hline & & Total & 127.252 & 100,0 & 60.409 & 100,0 \\
\hline \multirow{27}{*}{$\begin{array}{l}\text { OPERÁRIO } \\
\text { POPULAR }\end{array}$} & 4101507001001 & Arapongas1 & 18.117 & 3,2 & 8.197 & 3,3 \\
\hline & 4101507001002 & Arapongas2 & 15.777 & 2,8 & 7.327 & 3,0 \\
\hline & 4101507001004 & Arapongas 4 & 16.279 & 2,9 & 7.545 & 3,1 \\
\hline & 4101507001005 & Arapongas5 & 19.007 & 3,4 & 8.282 & 3,4 \\
\hline & 4103701001001 & Cambé1 & 20.895 & 3,7 & 9.395 & 3,8 \\
\hline & 4103701001002 & Cambé2 & 21.044 & 3,8 & 8.388 & 3,4 \\
\hline & 4103701001003 & Cambé3 & 15.236 & 2,7 & 6.926 & 2,8 \\
\hline & 4103701001004 & Cambé4 & 16.473 & 2,9 & 6.470 & 2,6 \\
\hline & 4109807001001 & Ibiporã & 42.153 & 7,5 & 17.471 & 7,1 \\
\hline & 4112702001001 & Jataizinho & 11.327 & 2,0 & 4.313 & 1,8 \\
\hline & 4113700999001 & Londrina1 & 16.625 & 3,0 & 7.145 & 2,9 \\
\hline & 4113700999002 & Londrina2 & 20.168 & 3,6 & 8.779 & 3,6 \\
\hline & 4113700999003 & Londrina3 & 24.171 & 4,3 & 10.283 & 4,2 \\
\hline & 4113700999004 & Londrina4 & 15.012 & 2,7 & 6.696 & 2,7 \\
\hline & 4113700999005 & Londrina5 & 30.227 & 5,4 & 12.962 & 5,3 \\
\hline & 4113700999006 & Londrina6 & 26.239 & 4,7 & 12.052 & 4,9 \\
\hline & 4113700999007 & Londrina7 & 32.406 & 5,8 & 14.289 & 5,8 \\
\hline & 4113700999008 & Londrina8 & 15.112 & 2,7 & 6.586 & 2,7 \\
\hline & 4113700999012 & Londrina12 & 24.943 & 4,4 & 11.698 & 4,8 \\
\hline & 4113700999014 & Londrina14 & 16.763 & 3,0 & 7.532 & 3,1 \\
\hline & 4113700999015 & Londrina15 & 23.428 & 4,2 & 10.388 & 4,2 \\
\hline & 4113700999016 & Londrina16 & 16.208 & 2,9 & 6.891 & 2,8 \\
\hline & 4113700999017 & Londrina17 & 16.284 & 2,9 & 5.899 & 2,4 \\
\hline & 4113700999021 & Londrina21 & 22.606 & 4,0 & 9.949 & 4,1 \\
\hline & 4113700999022 & Londrina22 & 14.997 & 2,7 & 6.783 & 2,8 \\
\hline & \multirow[t]{2}{*}{4122404001001} & Rolândia & 49.410 & 8,8 & 22.467 & 9,2 \\
\hline & & Total & 560.907 & 100,0 & 244.715 & 100,0 \\
\hline \multirow{22}{*}{ AGRÍCOLA } & 4100806001001 & Alvorada do Sul & 9.253 & 4,4 & 3.980 & 4,6 \\
\hline & 4101903001001 & Assaí & 18.045 & 8,6 & 6.587 & 7,5 \\
\hline & 4102802001001 & Bela Vista do Paraíso & 15.031 & 7,2 & 6.506 & 7,4 \\
\hline & 4103701001005 & Cambé5 & 14.538 & 7,0 & 6.463 & 7,4 \\
\hline & 4105102001001 & Centenário do Sul & 11.817 & 5,7 & 4.700 & 5,4 \\
\hline & 4108007001001 & Florestópolis & 12.190 & 5,8 & 4.748 & 5,4 \\
\hline & 4109203001001 & Guaraci & 4.919 & 2,4 & 2.055 & 2,4 \\
\hline & 4111902001001 & Jaguapitã & 10.932 & 5,2 & 4.707 & 5,4 \\
\hline & 4113700999023 & Londrina23 & 20.872 & 10,0 & 9.091 & 10,4 \\
\hline & 4113809001001 & Lupionópolis & 4.323 & 2,1 & 1.754 & 2,0 \\
\hline & 4116000001001 & Miraselva & 1.961 & 0,9 & 948 & 1,1 \\
\hline & 4119657001001 & Pitangueiras & 2.418 & 1,2 & 1.272 & 1,5 \\
\hline & 4120002001001 & Porecatu & 15.881 & 7,6 & 6.200 & 7,1 \\
\hline & 4120333001001 & Prado Ferreira & 3.152 & 1,5 & 1.465 & 1,7 \\
\hline & 4120507001001 & Primeiro de Maio & 10.728 & 5,1 & 4.404 & 5,0 \\
\hline & 4121307001001 & Rancho Alegre & 4.197 & 2,0 & 1.832 & 2,1 \\
\hline & 4122701001001 & Sabáudia & 5.413 & 2,6 & 2.402 & 2,7 \\
\hline & 4126405001001 & Sertaneja & 6.521 & 3,1 & 2.649 & 3,0 \\
\hline & 4126504001001 & Sertanópolis & 15.147 & 7,2 & 6.885 & 7,9 \\
\hline & 4126678001001 & Tamarana & 9.713 & 4,6 & 3.842 & 4,4 \\
\hline & 4128401001001 & Uraí & 11.876 & 5,7 & 4.944 & 5,7 \\
\hline & & Total & 208.927 & 100,0 & 87.430 & 100,0 \\
\hline \multicolumn{3}{|c|}{ TOTAL GERAL } & 897.086 & - & 392.554 & - \\
\hline
\end{tabular}

Fonte: IBGE - Microdados do Censo Demográfico - 2000. Elaboração das autoras. 
Tabela 5 - Percentual da tipologia socioespacial segundo as categorias sócio-ocupacionais da Região Metropolitana de Londrina nos anos de 2000 e 2010

\begin{tabular}{|c|c|c|c|c|c|c|}
\hline $\begin{array}{l}\text { TIPOLOGIA SOCIOESPACIAL } \\
(\mathbf{2 0 1 0 )}\end{array}$ & $\begin{array}{l}\text { ÁREA DE } \\
\text { PONDERAÇÃo }\end{array}$ & MUNICÍPIO & POPULAÇÃO & $\begin{array}{l}\text { PERCENTUAL DA } \\
\text { POPULAÇÃOO }\end{array}$ & $\begin{array}{l}\text { POPULAÇÃO } \\
\text { OCUPADA }\end{array}$ & $\begin{array}{l}\text { PERCENTUAL DA } \\
\text { POPULAÇÃO } \\
\text { OCUPADA }\end{array}$ \\
\hline \multirow{10}{*}{$\begin{array}{l}\text { SUPERIOR } \\
\text { MÉDIO }\end{array}$} & 4101507003003 & Arapongas3 & 13.366 & 3,0 & 6.946 & 3,2 \\
\hline & 4101507003005 & Arapongas5 & 19.986 & 4,5 & 9.784 & 4,5 \\
\hline & 4103701003002 & Cambé2 & 13.084 & 3,0 & 6.718 & 3,1 \\
\hline & 4109807003002 & Ibiporã2 & 26.652 & 6,0 & 11.720 & 5,4 \\
\hline & 4113700005001 & Londrina1 & 86.114 & 19,5 & 43.916 & 20,2 \\
\hline & 4113700005003 & Londrina3 & 95.374 & 21,6 & 46.814 & 21,5 \\
\hline & 4113700005005 & Londrina5 & 88.847 & 20,1 & 43.529 & 20,0 \\
\hline & 4113700005006 & Londrina6 & 84.678 & 19,2 & 41.037 & 18,9 \\
\hline & \multirow[t]{2}{*}{4122404003001} & Rolândia1 & 13.100 & 3,0 & 6.804 & 3,1 \\
\hline & & Total & 441.201 & 100,0 & 217.268 & 100,0 \\
\hline \multirow{20}{*}{$\begin{array}{l}\text { OPERÁRIO } \\
\text { POPULAR }\end{array}$} & 4101507003001 & Arapongas1 & 13.264 & 3,0 & 6.605 & 3,1 \\
\hline & 4101507003002 & Arapongas2 & 14.697 & 3,4 & 7.376 & 3,5 \\
\hline & 4101507003004 & Arapongas 4 & 20.096 & 4,6 & 10.084 & 4,8 \\
\hline & 4101507003006 & Arapongas 6 & 22.741 & 5,2 & 11.408 & 5,4 \\
\hline & 4102802001001 & Bela Vista do Paraíso & 15.079 & 3,5 & 7.178 & 3,4 \\
\hline & 4103701003001 & Cambé1 & 12.701 & 2,9 & 5.971 & 2,8 \\
\hline & 4103701003003 & Cambé3 & 13.622 & 3,1 & 6.803 & 3,2 \\
\hline & 4103701003004 & Cambé4 & 28.202 & 6,5 & 13.952 & 6,6 \\
\hline & 4103701003005 & Cambé5 & 29.124 & 6,7 & 15.237 & 7,2 \\
\hline & 4108007001001 & Florestópolis & 11.222 & 2,6 & 5.195 & 2,5 \\
\hline & 4109807003001 & Ibipora1 & 21.546 & 4,9 & 8.978 & 4,2 \\
\hline & 4111902001001 & Jaguapitã & 12.225 & 2,8 & 6.265 & 3,0 \\
\hline & 4112702001001 & Jataizinho & 11.875 & 2,7 & 4.647 & 2,2 \\
\hline & 4113700005004 & Londrina4 & 130.157 & 29,9 & 63.322 & 30,0 \\
\hline & 4113809001001 & Lupionópolis & 4.592 & 1,1 & 2.242 & 1,1 \\
\hline & 4120002001001 & Porecatu & 14.189 & 3,3 & 6.325 & 3,0 \\
\hline & 4122404003002 & Rolândia2 & 20.611 & 4,7 & 10.827 & 5,1 \\
\hline & 4122404003003 & Rolândia3 & 24.151 & 5,5 & 11.330 & 5,4 \\
\hline & 4126504001001 & Sertanópolis & 15.638 & 3,6 & 7.612 & 3,6 \\
\hline & & Total & 435.732 & 100,0 & 211.354 & 100,0 \\
\hline \multirow{15}{*}{ AGRÍCOLA } & 4100806001001 & Alvorada do Sul & 10.283 & 8,4 & 4.287 & 7,8 \\
\hline & 4101903001001 & Assaí & 16.354 & 13,3 & 7.136 & 13,0 \\
\hline & 4105102001001 & Centenário do Sul & 11.190 & 9,1 & 5.169 & 9,4 \\
\hline & 4109203001001 & Guaraci & 5.227 & 4,2 & 2.665 & 4,9 \\
\hline & 4113700005002 & Londrina2 & 21.531 & 17,5 & 9.275 & 16,9 \\
\hline & 4116000001001 & Miraselva & 1.862 & 1,5 & 902 & 1,6 \\
\hline & 4119657001001 & Pitangueiras & 2.814 & 2,3 & 1.495 & 2,7 \\
\hline & 4120333001001 & Prado Ferreira & 3.434 & 2,8 & 1.585 & 2,9 \\
\hline & 4120507001001 & Primeiro de Maio & 10.832 & 8,8 & 4.631 & 8,5 \\
\hline & 4121307001001 & Rancho Alegre & 3.955 & 3,2 & 1.780 & 3,3 \\
\hline & 4122701001001 & Sabáudia & 6.096 & 5,0 & 3.189 & 5,8 \\
\hline & 4126405001001 & Sertaneja & 5.817 & 4,7 & 2.391 & 4,4 \\
\hline & 4126678001001 & Tamarana & 12.262 & 10,0 & 4.967 & 9,1 \\
\hline & 4128401001001 & Uraí & 11.472 & 9,3 & 5.293 & 9,7 \\
\hline & & Total & 123.129 & 100,0 & 54.767 & 100,0 \\
\hline \multicolumn{3}{|c|}{ TOTAL GERAL } & 1.000 .062 & - & 483.390 & - \\
\hline
\end{tabular}

Fonte: IBGE - Microdados dos Censos Demográficos - 2000 e 2010. Elaboração: autoras, 2020.

Observa-se na distribuição das CATs pela região metropolitana que no tipo Superior Médio há um aumento significativo das categorias dirigentes e de nível superior no período, o que significa uma elitização, que se amplia de $15 \%$ para $45 \%$ da região, se estendendo a mais uma área em Arapongas, uma área em Cambé, uma em Ibiporã e uma em Rolândia.

Em sentido contrário, há um encolhimento de $62 \%$ para $44 \%$ de ocupação territorial entre 2000 e 2010 de tipo Operário Popular, com diminuição das categorias superiores e médias na década e, também, de todas as demais categorias, à exceção dos trabalhadores agrícolas que apresenta maior percentual nesse tipo em relação a 2000 , inclusive porque se espraiou para vários outros municípios da região metropolitana. Também o tipo Agrícola diminuiu de uma abrangência de $22 \%$ para $11 \%$ da área ocupada no período, que repercute a queda da presença de todas as ocupações. 
Na sequência, os tipos socioespaciais estão georreferenciados na base geográfica das APONDs da RML, cujas tipologias socioespaciais são identificadas por representações cartográficas com cores distintas (Figuras 3 e 4).

Figura 3 - Tipologia socioespacial da Região Metropolitana de Londrina no ano de 2000

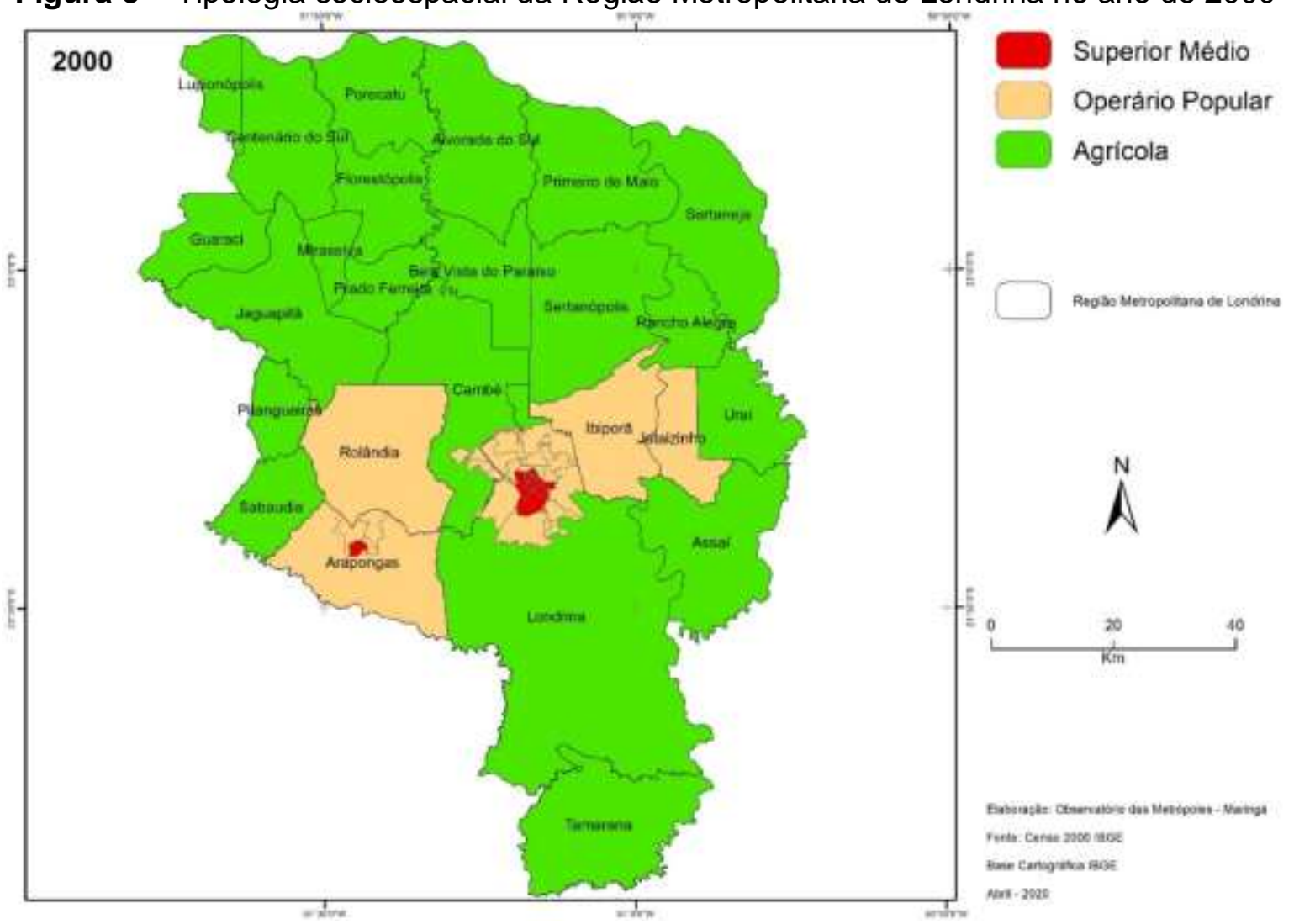

Fonte: IBGE - Microdados dos Censos Demográficos - 2000. Elaboração: Observatório das Metrópoles - Núcleo UEM/Maringá, 2020.

Observa-se que para 2000 as áreas que correspondem ao tipo Superior Médio (vermelho) estão concentradas na região central e adjacências de Londrina e em uma área localizada também no centro de Arapongas, não ocorrendo em qualquer outra porção da região, o que demonstra um processo de concentração de moradores de rendas altas nestas áreas. Observa-se que estas áreas centrais estão totalmente circundadas pelo tipo Operário Popular (creme), num grande anel, composto pela área urbana de Londrina, pelas demais áreas de Arapongas, por quatro áreas de Cambé e pelos municípios de Rolândia, lbiporã e Jataizinho. Na sequência, se destaca o tipo Agrícola (verde) que classifica uma área de Cambé e toda a porção sul de Londrina, mas, principalmente a maior parte das APONDs da região, sejam as que fazem limite imediato com as áreas do tipo Operário Popular ou as compostas por todos os demais municípios distantes do polo (Figura 3).

Verifica-se em 2010 que as ocupações de rendas altas, relativas aos estratos superiores, apresentam um espraiamento pela região metropolitana, num eixo que reúne 
áreas centrais de municípios que, em 2000, tinham uma composição socioespacial menos elitizada, quando apenas sete áreas centrais da cidade polo e uma de Arapongas assim se classificavam como tipo Superior Médio (vermelho). O tipo Operário Popular (creme) permanece na periferia norte do polo e no entorno das áreas superiores, dos municípios de Arapongas, Rolândia, Cambé e Ibiporã e, também, Jataizinho, Sertanópolis, Bela Vista do Paraíso, Jaguapitã, Florestópolis, Porecatu e Lupionópolis. O tipo Agrícola (verde) ocupa os municípios de Sabáudia, Pitangueiras, Guaraci, Centenário do Sul, Miraselva, Prado Ferreira, Alvorada do Sul, Primeiro de Maio, Sertaneja, Racho Alegre, Uraí, Assaí, Tamarana e a mesma área ao sul de Londrina que, em 2000, assim também se classificava (Figura 4).

Figura 4 - Tipologia socioespacial da Região Metropolitana de Londrina no ano de 2010

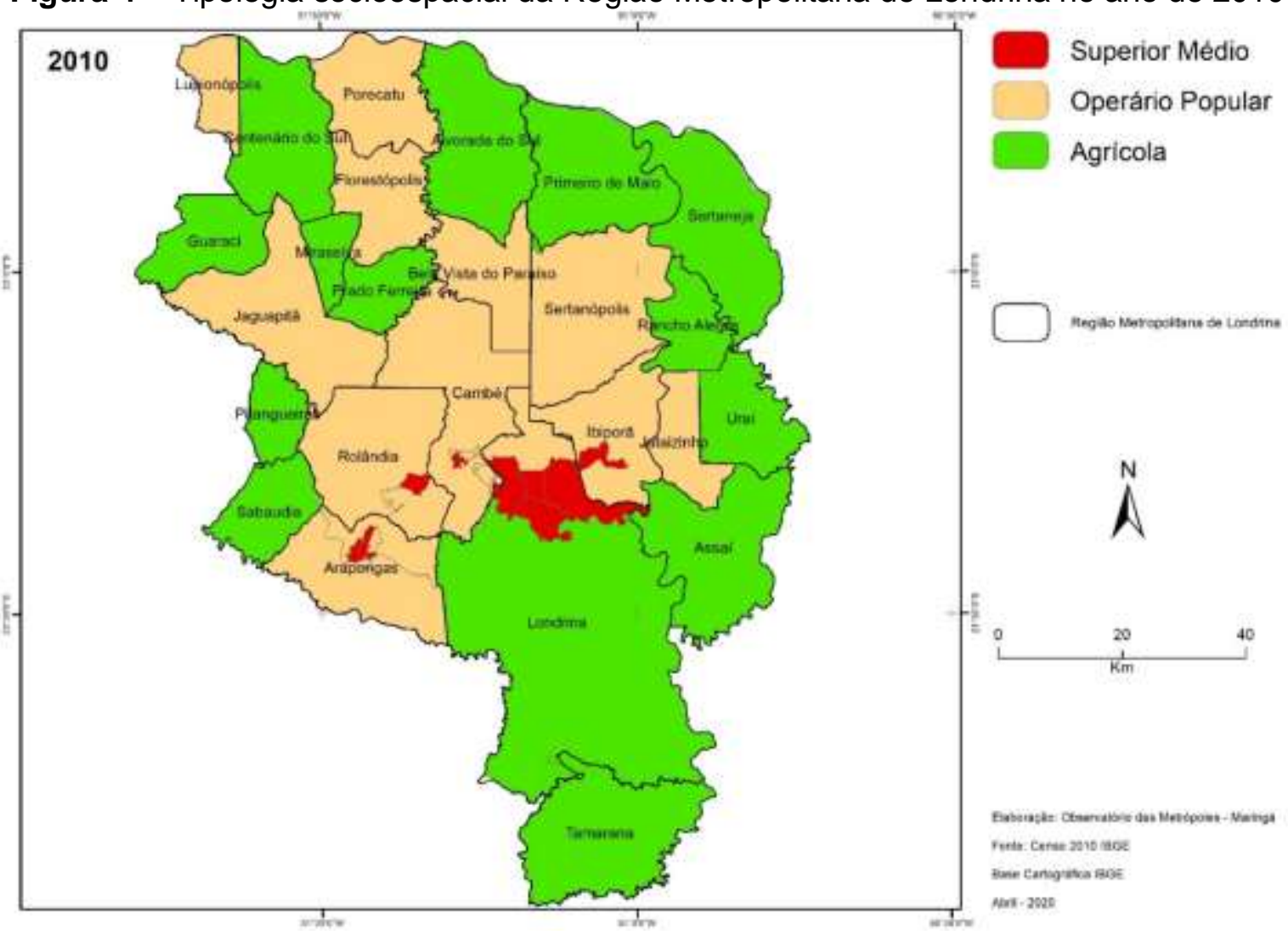

Fonte: IBGE - Microdados dos Censos Demográficos - 2010. Elaboração: Observatório das Metrópoles - Núcleo UEM/Maringá, 2020.

Apenas visualmente já é possível observar as mudanças e permanências no perfil socioespacial da RML em relação às características da ocupação dos moradores. Nota-se que, para ambos os períodos analisados, os tipos que representam as CATs das posições de hierarquia social superior ocupam a área central da cidade de Londrina e, em sentido contrário, os trabalhadores das categorias que identificam as baixas posições da hierarquia 
social se distanciam dessa área central, proporcionalmente à sua posição na ocupação, no mundo do trabalho.

\section{CONSIDERAÇÕES FINAIS}

As análises dos microdados dos Censos Demográficos do IBGE de 2000 e de 2010 possibilitaram a elaboração das CATs e da Tipologia Sócio-Ocupacional para a Região Metropolitana de Londrina e análise das mudanças e permanências no perfil socioespacial da região em relação às características dos moradores, a partir da sua ocupação. Nota-se que, para ambos os períodos analisados, os tipos que localizam as posições de hierarquia social superior ocupam as áreas centrais da cidade de Londrina e das demais assim classificadas e, em sentido contrário, as categorias que identificam as baixas posições da hierarquia social se distanciam dessas áreas centrais, relativamente à sua posição na ocupação de trabalho. Afinal, na cidade capitalista o território reproduz a estrutura social alicerçada em desigualdade, como resultado de processo que estabelece espaços para ricos e espaços para pobres. A ocupação residencial da Região Metropolitana de Londrina também é caracterizada por periferização da população de baixa renda, igualmente ao desenvolvimento do conjunto das cidades brasileiras. Ou seja, obedientes à lógica e aos interesses do mercado imobiliário e da sua correspondente, a especulação.

Todavia há um aspecto distinto na ocupação da RM de Londrina quando comparada à RM de Curitiba (DESCHAMPS, 2014), mas que se mostra semelhante à RM de Maringá (RODRIGUES; ACORSI e SOUZA, 2015). Trata-se do fato de que essas áreas centrais classificadas de tipo Superior Médio são partilhadas por moradores de estratos sociais altos e médios, o que permite vislumbrar um processo de baixa segregação, no qual as categorias de altas rendas não se concentraram de forma exclusiva em determinadas áreas, resultando em dois movimentos: i) se difundiram pela região metropolitana e; ii) passaram a residir em áreas centrais no município de Londrina, de Arapongas, de Rolândia, de Cambé e de Ibiporã, partilhando tais locais com os estratos médios da população ocupada. Isso mostra que não ocorre processo de elitização dos territórios, onde se concentrariam residentes das categorias superiores (talvez com exceção da região da Gleba Palhano onde, se sabe, se concentram os estratos de alta renda), inclusive porque ocorreu uma diminuição relativa desta categoria no período.

Por um lado, se observa a permanência de baixa presença da categoria dirigente na estrutura social da RML, tanto em 2000 quanto em 2010 e, por outro lado, se vê mudanças que ocorreram no período, principalmente em relação ao crescimento expressivo dos profissionais de nível superior e das ocupações médias e a diminuição dos pequenos empregadores e dos trabalhadores agrícolas. Esse aumento dos profissionais de nível 
superior significa que ocorreu a profissionalização do mercado de trabalho, com forte aumento tanto de autônomos como de empregados. Ressalta-se também o aumento do número relativo de professores de nível superior, refletindo o incremento de instituições de ensino. A terciarização da economia, um fenômeno crescente no país, parece ter tido comportamento distinto na região de Londrina no período, tendo em vista a menor incidência de ocupações tanto do terciário especializado quanto do não especializado. O que se vê é a proletarização do mercado e do território, com ganho relativo de trabalhadores do secundário.

As mudanças observadas inserem-se num conjunto de transformações econômicas e sociais do cenário nacional e internacional que atingiram a RML na década analisada. Transformações estas que emergem da perda de dinamismo industrial e da reestruturação produtiva, com redução da produção nacional e do emprego nesse setor, bem como com o aumento da informalidade, aspectos que estavam em curso no país todo desde os anos 1990, no contexto do projeto neoliberal implementado no país naquela década.

\section{REFERÊNCIAS}

BOURDIEU, Pierre. A miséria do mundo. Petrópolis, RJ: Vozes, 1997.

DESCHAMPS, Marley Vanice. Região metropolitana de Curitiba: estrutura social e organização social do território. In: FIRKOWSKI, Olga Lucia Castreghini de Freitas; MOURA, Rosa (eds.). Curitiba: transformações na ordem urbana. Rio de Janeiro: Letra Capital, 2014. p. 165-198.

FIRKOWSKI, Olga Lúcia Castreghini de Freitas; MOURA, Rosa. Regiões metropolitanas e metrópoles: reflexões acerca das espacialidades e institucionalidades no sul do Brasil.

Revista RA'EGA: O Espaço Geográfico em Análise, Curitiba, PR, v. 5, n. 5, p. 37-48, 2001.

IBGE. (2020). Estimativas da população residente para os municípios e para as unidades da federação com data de referência em 1 de julho de 2020 . Rio de Janeiro, RJ: IBGE, 2020. Disponível em: https://www.ibge.gov.br/estatisticas/sociais/populacao/9103estimativas-de-populacao.html?edicao=28674\&t=resultados. Acesso em: 31 ago. 2020.

IBGE. Malha municipal 2018. Rio de Janeiro, RJ: IBGE, 2018. Disponível em: ftp://geoftp.ibge.gov.br/organizacao_do_territorio/malhas_territoriais/malhas_municipais/.

Acesso em: 30 nov. 2018.

IBGE. Microdados censos demográficos 2000. Rio de Janeiro, RJ: IBGE, 2000. Disponível em: http://www.ibge.gov.br. Acesso em: 15 nov. 2018.

IBGE. Microdados censos demográficos 2010. Rio de Janeiro, RJ: IBGE, 2010. Disponível em: http://www.ibge.gov.br. Acesso em: 15 nov. 2018.

INSTITUTO PARANAENSE DE DESENVOLVIMENTO ECONÔMICO E SOCIAL- IPARDES. Perfil avançado das regiões. Região metropolitana de Londrina. Disponível em: http://www.ipardes.gov.br/perfil_municipal/MontaPerfil.php?codlocal=922\&btOk=ok. Acesso em: 27 abr. 2020.

MOURA, Rosa; HOSHINO, Thiago de Azevedo Pinheiro. Estatuto da metrópole: enfim, aprovado! Mas o que oferece à metropolização brasileira? Boletim Informativo 
Observatório das Metrópoles, Rio de Janeiro, RJ, p. 1-14, 2015. Estatuto da Metrópole: nova lei para a gestão metropolitana do Brasil? 29 jan. 2015. Artigos semanais. Disponível em:

https://www.academia.edu/10689071/ESTATUTO_DA_METRÓPOLE_ENFIM_APROVADO _MAS_O_QUE_OFERECE_À_METROPOLIZAÇÃO_BRASILEIRA. Ācesso em: 31 out. 2020.

PARANÁ. Casa Civil. Sistema Estadual de Legislação. Consulta: 1998 a 2014. Disponível em: https://www.legislacao.pr.gov.br/legislacao/pesquisarAto.do?action=listar\&opt=t\&site=1. Acesso em: 27 abr. 2020.

RIBEIRO, Luiz Cesar de Queiroz; LAGO, Luciana Corrêa do. O espaço social das grandes metrópoles brasileiras: Rio de Janeiro, São Paulo e Belo Horizonte. Revista Brasileira de Estudos Urbanos e Regionais (RBEUR), Recife, n. 3, p. 111-129, out. 2000.

RIBEIRO, Luiz Cesar de Queiroz; RIBEIRO, Marcelo Gomes. Análise social do território: fundamentos teóricos e metodológicos. Rio de Janeiro: Letra Capital, 2013.

RODRIGUES, Ana Lúcia; ACORSI, Clédina Regina Lonardan; SOUZA, Paulo Roberto de. Estrutura e organização social do território da Região Metropolitana de Maringá. In:

RODRIGUES, Ana Lúcia (Ed.). Maringá: transformações na ordem urbana. Rio de Janeiro: Letra Capital, 2015. p. 147-184.

Recebido: junho de 2020. Aceito: novembro de 2020. 